\title{
Polifacetismo y productividad de los talleres familiares de pintura de Granada en el siglo XVIII
}

\author{
Ana María Gómez Román \\ Universidad de Granada \\ anaroman@ugr.es
}

RESUMEN: La proliferación de los talleres familiares de pintura en Granada, a lo largo del siglo XVIII, constituye un episodio fundamental en relación a la historia de la ciudad en el ámbito artístico. En este artículo reconstruimos, en base a información documental, cuáles eran los más relevantes y activos en esa centuria, aportando referencias sobre algunos pintores hasta ahora desconocidos.

PALABRAS CLAVE: Talleres gremiales; Pintura; Pintoras; Marín Chaves; Sanz Jiménez; Granada; Siglo XVIII.

\section{Versatility and Productivity of Family Painting Workshops in Granada in the $18^{\text {th }}$ Century}

ABSTRACT: The proliferation of family painting workshops in Granada, during the 18th century, is a fundamental episode of the city's artistic history. In this article we reconstruct, on the basis of documentary information, which were the most important and active workshops in that century, providing references to some painters unknown until now.

KEYWORDS: Guild Workshops; Painting; Painters; Marín Chaves; Sanz Jiménez, Granada, $18^{\text {th }}$ Century.

Recibido: 15 de febrero de 2021 / Aceptado: 7 de junio de 2021.

En la ciudad de Granada advertimos que a lo largo del siglo XVIII los talleres artísticos fueron los lugares habituales de aprendizaje, de manera que la formación gremial, y en especial la que se hacía dentro del ámbito familiar, fue la praxis más común para un considerable número de jóvenes. Es por ello que la Escuela de Dibujo de Granada, más tarde Real Academia de Bellas Artes Nuestra Señora de las Angustias, tras su fundación en 1777 pretendió desterrar este tipo de método de instrucción en favor de un conocimiento más amplio, y regulado, de las disciplinas artistas. Todo ello a través de programas docentes impartidos por profesores cualificados y con regulares muestras de las habilidades adquiridas por los estudiantes mediante las llamadas pruebas mensuales. Con todo, también se daría el caso de artistas que, pese a recibir una primera formación dentro del entorno familiar, decidieron incorporarse de alguna manera a la dinámica de dicha escuela presentándose a los respectivos concursos generales de convocatoria pública que eran organizados entre esta y la Real Sociedad Económica de Amigos del País, institución bajo la que estaba al amparo, y que premiaban sus destrezas aunque no fueran necesariamente alumnos del referido centro.

Por otra parte no todos los pintores se dedicaron exclusivamente a las bellas artes. Algunos practicaron el oficio en el más puro sentido gremial al atender tareas de composición de bastidores y lienzos, mientras que otros se especializaron en disciplinas afines que incluían desde la restauración hasta el dibujo topográfico, el charolado e incluso la decoración mobiliar. Asimismo hay otro tema que merece la pena tener en cuenta en relación a estos linajes de artistas. Nos referimos al origen converso de algunas estirpes familiares como los Marchena, los Molina Mendoza o los Marín Chaves. Según testimonios de la época todos ellos eran descendientes de islamizantes, circunstancias que justifican un constante interés por ejempli-

Cómo citar este artículo: GÓMEZ ROMÁN, Ana María, «Polifacetismo y productividad de los talleres familiares de pintura de Granada en el siglo XVIII», Boletín de Arte-UMA, n. ${ }^{\circ}$ 42, Departamento de Historia del Arte, Universidad de Málaga, 2021, pp. 131-142, ISSN: 0211-8483, e-ISSN: 2695-415X, DOI: http://dx.doi.org/10.24310/BoLArte.2021.vi42.11966 


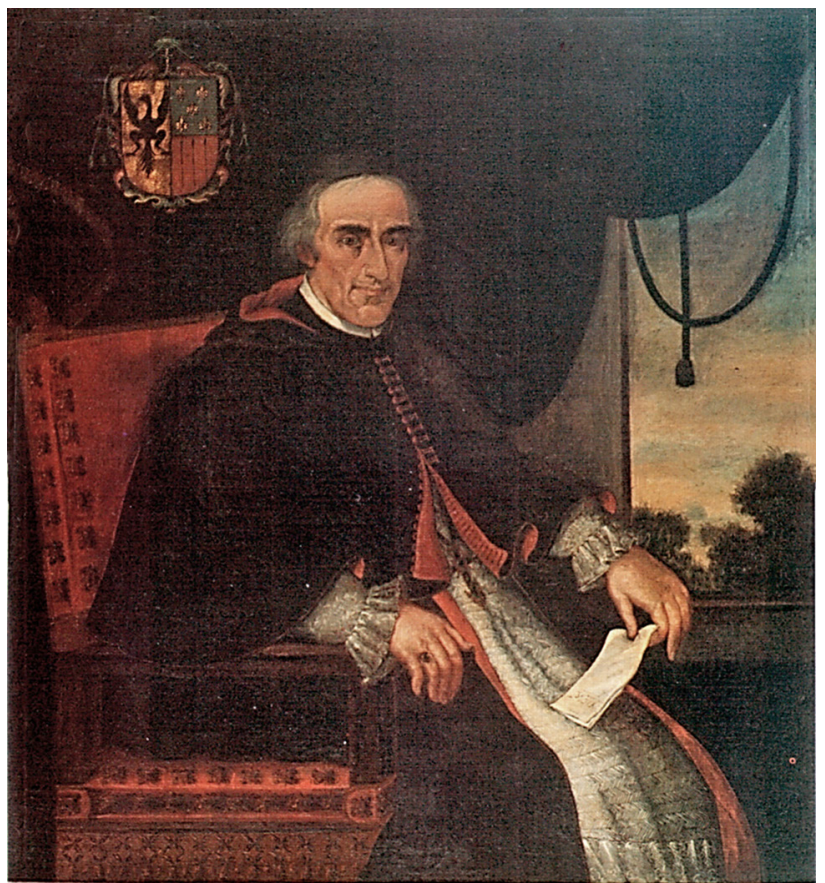

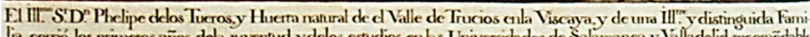

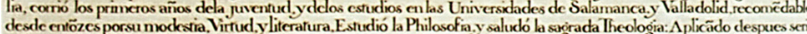

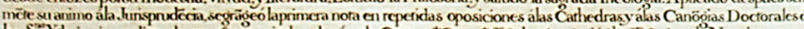

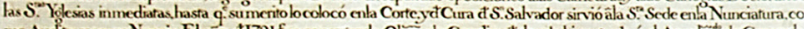

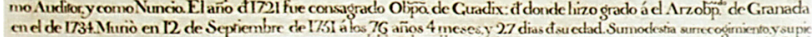

1. Manuela Isidora de Rueda, Felipe de Ios Tueros. Curia, Granada

ficar su vida pública y una obsesiva dedicación a la pintura religiosa con la idea de evadir cualquier señalamiento social en relación a sus verdaderas señas de identidad familiar de carácter criptoislámico.

Otra cuestión a resaltar es que, afortunadamente, cotejamos algunos ejemplos de mujeres artistas formadas en el ámbito familiar y que, a la postre, gozaron de una cierta consideración entre sus coetáneos. De hecho, desde finales del XVII tenemos algunas referencias de pintoras cuyas habilidades artísticas la adquirieron bajo la supervisión paterna. Sirva el caso de María (nacida ca. 1670), una de las hijas del pintor Juan de Sevilla que se manejó con bastante soltura con los pinceles y de la cual Gómez-Moreno afirmaba haber visto un cuadro suyo en una colección particular, en concreto una Inmaculada (Moya, 2004: 657). Otro ejemplo lo hallamos en la figura de Manuela Isidora Antonia de Rueda, nacida en 1725 e hija del matrimonio conformado por el también pintor Jerónimo de Rueda Navarrete y Cipriana Josefa Pérez ${ }^{1}$. Este último era uno de esos artistas que viene a cubrir la nómina de los más relevantes y más solicitados de la primera mitad del XVIII en la ciudad y cuyo taller lo tenía instalado en la feligresía de San Justo y Pastor ${ }^{2}$. Sus obras se caracterizan por un estilo amanerado, heredado por su hija, siendo quizá lo mejor de su producción la Inmaculada que luce el retablo central de la iglesia parroquial de Cúllar Vega (Reyes, 1995: 83). De Manuela Isidora conocemos el retrato firmado del arzobispo Felipe de los Tueros, conservado en el palacio arzobispal (Moya, 2004: 659), muy en consonancia con los modelos retratísticos de los pintores granadinos y en especial con el de Martín de Ascargorta pintado por José Risueño (Castañeda, 2006: 152-153) [1]. A estas pintoras habría que añadir el nombre de María Serafina de La Chica, que se comentará más adelante por su vinculación con la Escuela de Dibujo.

Por consiguiente, para arrojar luz sobre estos talleres, cuyos integrantes en la mayoría de los casos son artistas bastantes desconocidos, debemos partir de una base documental que los contextualice como pintores activos teniendo en cuenta que, a lo largo del siglo XVIII, tuvieron un considerable papel tanto en el desarrollo de algunos de los programas artísticos de la ciudad, y su ámbito de influencia, como en otras disciplinas relacionadas con el mundo del arte.

\section{Los Marchena}

Tres fueron los integrantes de este taller que tuvieron la consideración de maestros. El primero al que hacemos referencia es Salvador de Marchena, quien vio la luz en la década de los sesenta del siglo XVII y expiró el 3 de febrero de $1759^{3}$. Su taller osciló por varias viviendas albaicineras, entre ellas la casa número 46 de la calle Jesús María y José (1717) o la casa número 3 de la calle del Gallo ${ }^{4}$. En sus últimos años de vida, dado que su mujer había fallecido en 1740, estuvo atendido, además de un criado de nombre Manuel Martínez, por María Trenco, hermana a su vez de Beatriz quien fuera pareja del imaginero Torcuato Ruiz del Peral. Estuvo casado con María Leonarda de Mendoza -natural de Martos quien a su vez provenía de otra familia de pintores-, y fueron padres de Tomás, Francisco y Esteban Cecilio de Marchena. Por lo que respecta a Francisco, hijo del anterior, contrajo esponsales el 21 de febrero de 1689, en el oratorio de la que fuera casa de Pedro Atanasio de Bocanegra, con Isabel Josefa de 
Herrera y Marigal ${ }^{5}$. Y en 1740 trabajó como oficial del pintor José Hidalgo en la decoración mural del Camarín de la Basílica de la Virgen de las Angustias.

Centrándonos en la biografía de Esteban Cecilio de Marchena sabemos que contrajo esponsales con Esperanza González, con quien tendría varios hijos de los cuales, que sepamos, dos se dedicaron a la pintura: Basilio y Francisco ${ }^{6}$. El primero de ellos, Basilio Damián Marchena, nació el 14 de junio de 1714 y desposó en 1735 con Cecilia Alcocer ${ }^{7}$. El dato más relevante en torno a su vida es la mención en su expediente matrimonial del testimonio del hermano de la contrayente que afirmaba que no era descendiente de cristianos viejos $^{8}$. A pesar de caer sobre él la sospecha de su ascendencia islamizante no dejó de trabajar y en la década de los treinta era ya un artista lo suficientemente cualificado con significativos contactos laborales con otros tantos pintores, entre ellos el anteriormente mencionado José Hidalgo quien sería padrino de una de sus hijas nacida en noviembre de 1736. Como maestro pintor su retribución anual, según el Catastro de la Ensenada, era de unos 1080 reales y tuvo como oficial a Bernardo García quien percibía, según la misma fuente, unos 540 reales anuales ${ }^{9}$. Su vida se apagó en 1750.

Con todo, el más relevante de toda esta saga sería el otro hijo de Esteban, Francisco Marchena González (17201789), del cual tenemos abundantes datos como para construirle una pequeña semblanza ${ }^{10}$. Sabemos que el 11 de febrero de 1752 formó vida marital con Jerónima Ramos Narváez, y con la que tuvo a Salvador y Felipe ${ }^{11}$. En cuanto a su actividad laboral se dio a conocer como pintor decorador, y durante años tuvo como oficial a Francisco Calzado. Dentro de su especialidad como adornista dominaba con soltura la decoración mural de fachadas, tal y como se desprende de su ofrecimiento en 1763 para decorar el frontis del palacio de los marqueses de Peñaflor en Écija (Sevilla) aunque finalmente sería el pintor madrileño Antonio Fernández quien las llevaría a la práctica entre 1764-1765 (Martín y Valseca, 2000: 168). Trabajó para la orden hospitalaria donde pintó, junto con su oficial José Martín, varios espacios del complejo asistencial. Primero, hacia 1765, intervino en la escalera claustral del hospital granadino, y en 1771 completaba dos cartelas murales de su claustro además de retocar la pintura mural de la iglesia y del panteón ${ }^{12}$. De igual modo, cultivó el óleo y en este sentido nos consta la existencia de dos cuadros de su mano. Por una parte, La imposición de la casulla a san Ildefonso (1763); y por otra, un lienzo de grandes dimensiones del Árbol de la orden Hospitalaria (Museo de la Ciudad de Antequera, 1761). Este último fue encargado por Nicolás Castaño de Rivera y Juana Carrasquilla para el Hospital de San Juan de Dios de Antequera, siendo copia del que había pintado Diego Sánchez Sarabia con el mismo asunto para el zaguán del centro hospitalario de Granada (Alabau, 2015: 412). En la plenitud de su carrera, a pesar de que su trayectoria parecía ir por buen camino, se vio abocado a aceptar cualquier tipo de trabajos dadas las dificultades de labrarse camino en un mercado cada vez más complicado. Por consiguiente, a comienzos de 1776 aceptó sin ningún problema el encargo que le hizo el cabildo de la catedral de Granada de dorar las bóvedas y la entrada de la capilla donde debía colocarse la nueva imagen escultórica de San Cecilio, obra de Miguel de Verdiguier ${ }^{13}$. Unos meses más tarde, en concreto el 16 de agosto de 1776 , formalizaba la entrega de los cuatro escudos de armas del arzobispo Antonio Galván, cobrando por ello unos 150 reales, que debían ornamentar las esquinas del entarimado que se había compuesto para el acto de toma de posesión del mitrado como nuevo metropolitano.

\section{Los Molina Mendoza}

En este caso analizamos la trayectoria de dos hermanos, Jacinto y Felipe, aunque sabemos que un tercero de nombre José (nacido en 1685) también fue maestro pintor. Eran hijos de Manuel de Molina y Mendoza y Juana de Cisneros León y Ayala, familia de moriscos tardíos (Soria, 2012: 210). Por lo que se refiere a Jacinto de Molina Mendoza y Cisneros, alumbrado en Granada en 1669 y bautizado el 24 de marzo en la parroquia de San Juan de los Reyes, se convirtió en uno de esos artífices que viene a completar la nómina de los pintores activos, y más conocidos, de la primera mitad del XVIII en Granada. En vida fue una persona muy respetada gozando del apreció de sus contemporáneos por su afable carácter y buen hacer. Por lo que respecta a sus cuadros recuerdan la manera de José Risueño, del que conocía muy bien su estilo desde el momento en que estableció su domicilio próximo al de este maestro en la parroquial de Santa Ana, y con el que tuvo la oportunidad de colaborar como su ayudante en el ciclo pictórico del convento de mercedarios descalzos o de Belén. Aunque, a diferencia de Risueño, su obra se caracteriza por 
emplear colores más apagados y por una mayor concreción en el dibujo. Sin embargo, en sus comienzos estuvo vinculado, por una parte con el entorno de Miguel Pérez de Aibar -un pintor bastante interesante fallecido en 1697 que había asumido, a su vez, el estilo de Alonso Cano a través de su amistad directa con Juan de Sevilla-; y por otra, con Francisco Gómez de Valencia -vástago del también pintor Felipe Gómez de Valencia-. Fue, a su vez, miembro de la elitista Hermandad de la Escuela de Cristo, al igual que en su día lo había sido su maestro Pérez de Aibar, siendo conocido entre sus coetáneos por ello tanto con el sobrenombre de «hermano Mendoza» o «el tío Jacinto». Por otra parte, el 25 de febrero de 1702 contrajo esponsales con Josefa Noguera Mendoza, nacida en Abla y viuda de Francisco Muros ${ }^{14}$. Su felicidad se vio truncada en mayo de 1739 cuando falleció la antedicha quien sería enterrada en la iglesia de Santa Ana, el mismo lugar que acogería los restos mortales del pintor en 1747.

En cuanto a la trayectoria pictórica de Jacinto de Molina fue en la década de los veinte, y coincidiendo con su ascenso como pintor, cuando decidió trasladar su domicilio desde el Albaicín a la feligresía de Santa Ana, en concreto a la calle Cañuela número 210. Allí acogería entre los años de 1728 y 1729 a un joven discípulo de nombre Francisco de Torres $^{15}$. A partir de entonces comenzó a estar muy solicitado hasta el punto que muchas de sus obras ornamentarían parte de los muros de algunos de los principales conventos granadinos. Por ejemplo, para los trinitarios de Gracia pintó dos cuadros: un Éxtasis de San Miguel de los Santos y el retrato del Venerable Padre Fray Bernardo Monroy Martín (Museo Provincial de Bellas Artes, Granada) [2]; y para el convento de San Francisco Casa Grande un San Miguel. En el Museo de Bellas Artes de Granada se conservan otras tantas obras suyas que dan muestra de su estilo, entre ellas una Alegoría de la Inmaculada Concepción; la Aparición de San Pedro Nolasco a un rey Moro, en este caso dentro del ciclo del convento mercedario de Belén; un Ecce Homo; un San Wenceslao; el Retrato del pintor Miguel Pérez de Aybar -donado por Manuel Gómez Moreno y que en origen fue un encargo de la propia Escuela de Cristo tras el deceso del pintor de Tudela en 1697-; y el Retrato de Jerónimo Tomás de Casanova ${ }^{16}$. Según Giménez Serrano en el momento de inauguración en 1839 del museo provincial de Granada entre sus fondos se atesoraban unos veintinueve lienzos de este artista (Giménez, 1846: 320-321).
Respecto a Felipe de Molina Mendoza, (fallecido el 13 de abril 1745), su carrera fue menos prolija que la de su hermano. Estuvo casado con Ana Bueno Martínez, nacida en La Cuesta -obispado de La Calahorra- y tuvo su obrador en pleno Albaicín, en concreto en la calle Cobertizo de la feligresía de San Miguel. Allí estableció un importante nexo de unión con otros artistas asentados en esta misma demarcación parroquial. Entre ellos figuraban el imaginero Torcuato Ruiz del Peral, el pintor Salvador de Marchena y el imaginero Diego de Mora, primo de los afamados escultores José y Diego Antonio de Mora y López, al que posiblemente le realizó labores de policromado de sus esculturas. La confraternidad entre ambos fue tal que Mora sería compadre de varios de sus hijos, en concreto de Josefa nacida en 1710, de José Antonio (1713) y de José Ignacio (1718) ${ }^{17}$. Aunque Felipe, que sepamos, tuvo más descendencia: Francisca (1702) y Diego Antonio (1705). Este último llegó a alcanzar el grado de maestro pintor, teniendo su taller en el Albaicín según recoge el Catastro, al igual que su otro hermano José Ignacio ${ }^{18}$.

\section{Los Ñúñez}

El caso de esta unidad familiar es diferente a las anteriores por orientar su actividad laboral, básicamente, al ámbito comercial. En primer lugar analizamos la figura de Vicente Núñez García nacido hacia 1714 en la ciudad de Murcia. Este, desde mediados de siglo ya estaba plenamente activo en Granada trabajando como oficial carpintero y como pintor, tal y como referencia el Catastro, y percibiendo por ello una retribución anual de unos 720 reales $^{19}$. En realidad, en calidad de charolista regentaba un negocio ubicado en la calle Zacatín donde, en sus inicios, vendía desde telas de lienzos hasta todo tipo de pinceles o materiales de pintura. En estos primeros años de andadura laboral solía auxiliarse por su hermano Pedro (López-Guadalupe y López-Guadalupe, 1996: 186). Una vez alcanzada la estabilidad económica contrajo esponsales con Teresa de Vílchez en 1748 con quien tendría, que sepamos, dos hijos: Rosa y José. Este último, nacido en ese mismo año de 1748, además de estar empleado en la empresa familiar, con el tiempo enfocó su orientación profesional hacia la práctica de la pintura al igual que haría su propio padre ${ }^{20}$. De hecho, la trayectoria de Vicente Núñez dio un considerable giro desde el momento en que comenzó a ofertar a su clien- 
tela, además de un tipo de mercancía más surtida que incluía desde estampas y cornucopias que el mismo remataba pintándolas, algún que otro lienzo de su mano junto con cuadros pequeños de carácter devocional alhajados con ricos marcos. Es por ello que tuvo múltiples y distinguidos clientes entre los cuales estaba el VI conde Luque para quien compuso, con destino al oratorio privado del aristócrata en su palacio de Algarinejo, un pequeño «juguete» de siete cuartas con las figuras de san Juan evangelista, vestido de sacerdote ante el altar con todos sus ornamentos, Cristo, y a los pies la Virgen, y a los lados san Ignacio mártir y san Bonifacio ${ }^{21}$.

Con todo, Vicente Núñez sería más conocido por su faceta como docente. Cuando Diego Sánchez Sarabia, que había sido uno de los instigadores de la fundación de la Escuela de Dibujo en 1777, se trasladó a la localidad almeriense de Fondón para decorar la cúpula del camarín del Cristo de la Luz, fue Núñez quien se hizo cargo de las clases de principios y del natural en sustitución del anterior (Salas, 1966: 60). De este modo, se convirtió en flamante director de pintura mientras que su hijo José lo sería como teniente director. Sin embargo, a finales de 1781, ambos se vieron abocados a renunciar a sus puestos a raíz, por un lado, de las numerosas críticas recibas sobre sus particulares métodos docentes, poco prácticos y más cercanos a las prácticas artesanales que a los nuevos postulados académicos; y por otro, a un nuevo proyecto laboral que requería la participación de ambos dentro del programa ornamental de la Colegiata de Santa Fe. Por consiguiente esta fue la razón por la que dieron por concluidas sus obligaciones académicas para concentrarse, de manera exclusiva, en esta lucrativa empresa. En concreto padre e hijo decorarían las cajas del órgano y del falso órgano del expresado templo, pintando los retratos de los Reyes Católicos, Carlos III y su esposa y Carlos IV y María Luisa de Parma junto con David tocando el arpa y Santa Cecilia.

\section{Los Sanz Jiménez}

La familia de pintores Sanz Jiménez, o Sáenz Jiménez como aparecen referenciados en alguna documentación, junto con los Marín fueron quienes desde mediados del siglo XVIII tuvieron en Granada una mayor proyección en comparación con el resto. En este caso el patriarca fue Nicolás Sanz Jiménez de Cisneros, nacido el 10 de mayo de 1683 en el seno del

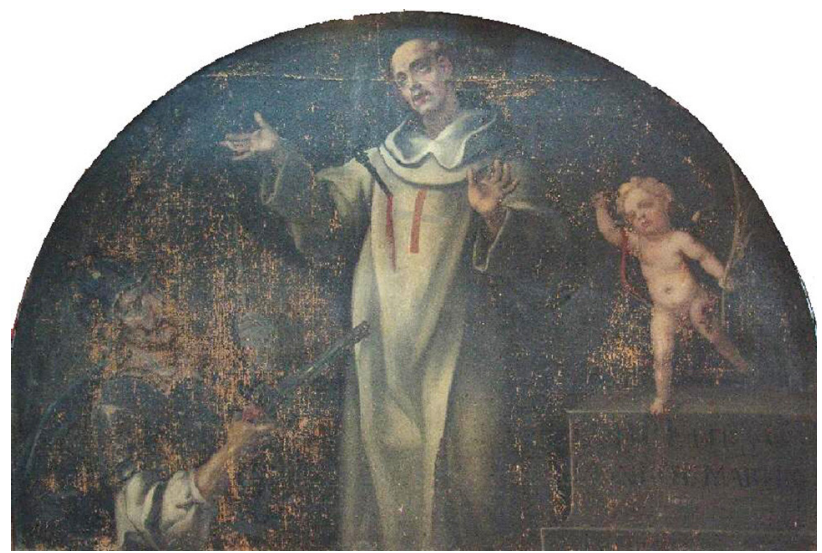

2. Jacinto de Mendoza, Fray Bernardo Monroy. Museo de Bellas Artes, Granada

matrimonio formado por José Sanz Jiménez y Eufrasia Teresa Pérez Rico, quien tras contraer esponsales con Seberina Mariana Guerrero Pérez, sería padre de los pintores Manuel y Luis y de otros tantos vástagos: Miguel Antonio, Felix María, Antonia y Rosalía22. En relación a esta familia, y para entender su particular situación social, resulta revelador un dato clave sobre Seberina Mariana. Esta había nacido el 13 de enero de 1690 y era hija extramatrimonial de un hermano de Eufrasia Teresa Pérez -posiblemente del eclesiástico y aclamado poeta Tomás Pérez Rico-. Esta circunstancia, a la postre, le supondría a la joven un grave inconveniente en el momento de formalizar su enlace con el padre de nuestros artistas puesto que, además de ser primos, destapaba a ojos de la sociedad su delicada situación familiar. A pesar de ello, finalmente obtuvieron el pertinente permiso, mediante auto emitido el 25 de septiembre de 1712, que les permitía contraer esponsales. En 1717 cotejamos, solo en ese año y quizá por razones laborales, que la pareja residía en la casa número 18 del Aljibe del Rey, la misma vivienda que ocupaba la familia de los Sarabia y a la que pertenecía el pintor Diego Sánchez Sarabia. Posteriormente la pareja se trasladó a una casa de la calle Molino, curato de San Juan de los Reyes, donde en 1756 le sobrevino la muerte a Nicolás ${ }^{23}$. Aunque desconocemos cuál era su oficio ambos eran «pobres miserables de solemnidad y viven de la industria y trabajo de sus manos» ${ }^{24}$. Por el contrario sus hijos Manuel y Luis sí alcanzaron una mayor estabilidad económica al convertirse en pintores al igual que Félix quien también aparece reseñado a la edad de 33 años en el Catastro de la Ensenada pero como oficial dorador ${ }^{25}$. 


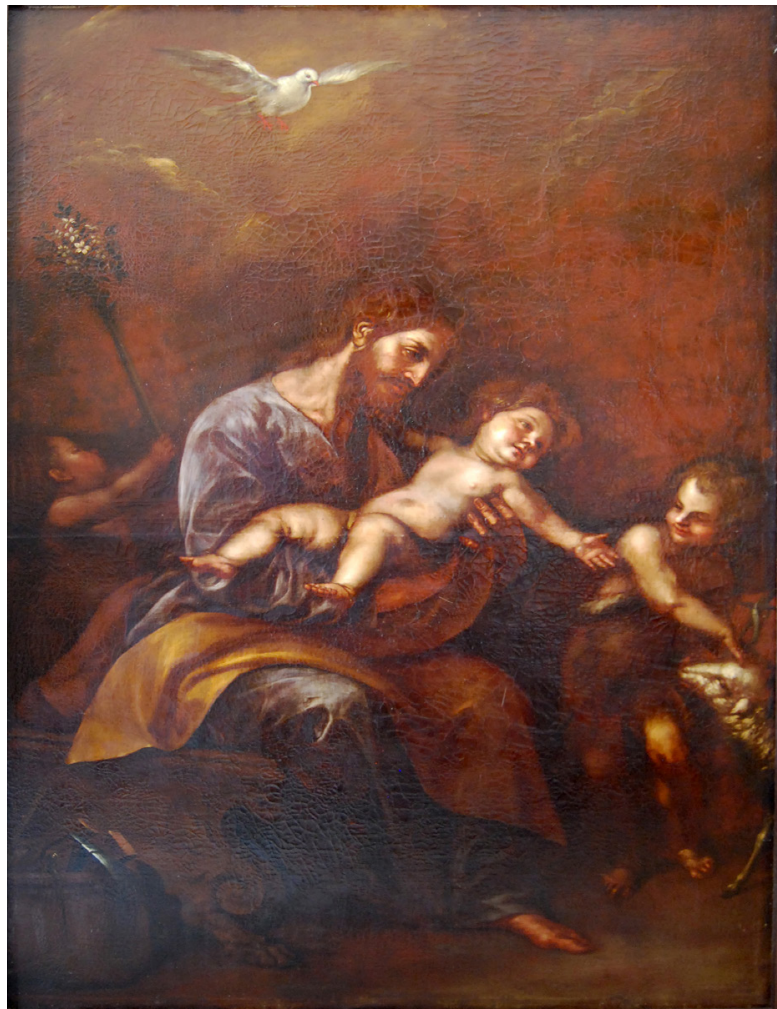

3. Manuel Sanz Jiménez, San José, el Niño y San Juan. Residencia de Padres Agustinos, Granada

Por lo que respecta a Manuel José Sanz Jiménez, nació en julio de 1713 y fue bautizado el día 4 de ese mes en la iglesia de San Miguel26. Tuvo una extensa trayectoria como pintor hasta su óbito que se produjo en 1774 siendo sepultado en la iglesia de Santa Ana, su parroquia por entonces, el 30 de noviembre de ese año ${ }^{27}$. En cuanto a su formación esta tuvo lugar en el entorno del muralista Martín de Pineda, artista que en 1729 emprendió la restauración de las pinturas del Peinador de la Alhambra y con el que Sanz colaboró en calidad de oficial. Para mediados de siglo su nombre ya había transcendido más allá de tierras granadinas hasta el punto que en junta ordinaria de la Real Academia de Bellas Artes de San Fernando, celebrada el 14 de octubre de 1756, se le propuso para que copiara «varios retratos de los Reyes Moros» del palacio de los Leones de la Alhambra. Se trataba de reproducir a lienzo la pintura sobre cuero de la alcoba de la Sala de los Reyes por lo que Academia se cuidó de enviar una comunicación oficial al presidente de la Chancillería, a la sazón Manuel de Villena, instándole a que emprendiera los respectivos trámites con el pintor dado que era «discípulo de la Academia de conocida avilidad» (Rodríguez, 1990: 226227). No obstante, debido a sus múltiples ocupaciones, finalmente Sanz Jiménez no cumplió con dicho cometido por lo que en 1760 la institución madrileña no tuvo más remedio que instar, esta vez al alcaide de la Alhambra Luis de Bucareli, para que buscara otro artista capaz de hacerlo, siendo finalmente el elegido Diego Sánchez Sarabia. En relación a su producción artística en 1740 pintó el testero del coro y los nichos de la iglesia conventual del Corpus Christi de las agustinas recoletas y de igual modo retocó la Virgen de la Consolación o de la Correa que atesora dicha comunidad ${ }^{28}$. Con destino al retablo de San José de la iglesia de los Hospitalicos ejecutó una de sus mejores composiciones un San José, el Niño y San Juan (Granada, Residencia de Padres Agustinos) [3]. Se trata de una copia de un lienzo similar que había realizado Bocanegra para el convento de las Descalzas de Antequera y que, a su vez, era una versión libre del famoso cuadro de Alonso Cano de La Sagrada Familia (Convento del Ángel Custodio, Granada). Pero Manuel Sanz practicó otros géneros como el retrato y en este sentido destaca el que hizo del arzobispo Onésimo de Salamanca (Granada, Curia) [4] (Hernando, 1857: 50). Por lo demás, fue dueño del vínculo que fundó en Ciudad de México Juan Cebrión Sanz y que a su muerte pasó, por disposición testamentaria, a su hermano Miguel. Finalmente en su haber le cabe el mérito de ser el maestro e instructor de toda una generación de pintores, entre ellos los hermanos Marín Chaves.

Con todo, sería su hermano Luis Sanz Jiménez el más referenciado por la historiografía artística local. Fue alumbrado en 1729 y bautizado el 26 de febrero en la iglesia de San Miguel. El 6 de abril de 1753 contrajo matrimonio, en la iglesia de San Juan de los Reyes, con Vicenta Íñiguez de Balgogera Soto, viuda de Francisco de Samos, actuando como testigos los imagineros Torcuato Ruiz del Peral y Diego Sánchez Sarabia y el pintor Francisco Marchena. En cuanto a su vida laboral empezó a despuntar a partir de 1739, año en que confraternizó con el muralista José Hidalgo. A diferencia de su hermano podemos considerarlo como un artista que no solo dominó la pintura sino que, al igual que otros pintores de la época, restauró y tasó obras de arte e incluso tuvo incursiones en otras tantas tareas afines. Por ejemplo, en 1788 suministró los clavos para la compostura del retablo de la Santa Cruz de la Capilla Real' ${ }^{29}$. 
En relación a su estilo Gómez-Moreno González afirmaba al respecto: «sus pinturas se distinguen por la dureza de las sombras y medias tintas que aparecen muy pardas y recortadas haciendo el efecto de manchas producido por la alteración del color sobre la imprimación del rojo de almagra, muy usado entonces, defecto que se observa en todos los pintores de la época» (Moya, 2004: 660). Entre sus primeras obras conocidas está el retrato del Padre Maldonado, firmado en 1756 y atesorado en la sacristía de la iglesia de Santiago (Gallego, 1982: 320). Sin embargo, sus trabajos más documentados son aquellos emprendidos para la catedral de Granada. Así el 14 de mayo de 1763 hizo entrega de dos lienzos, San Juan Nepomuceno y San Cristóbal, con destino a la capilla de Santa Casilda. Un mes más tarde, y para esta misma capilla, pintó y encarnó el medallón «que hace respaldo al nicho de Sta Casilda». El 14 de mayo de 1771 volvía a proporcionar otros dos cuadros más, pero esta vez con destino a la capilla de la Santa Cruz (hoy capilla de la Virgen del Carmen), San Pedro de Alcántara y la visión de la Santa Cruz y San Antonio de Padua con el Niño y por los que cobró unos 600 reales. Además de esta participación en el templo metropolitano, para la iglesia de Santiago pintó, junto con el retrato antes mencionado, los de los Reyes Católicos, El arzobispo Juan Manuel Moscoso, y un Apostolado que se conserva incompleto (Gómez-Moreno, 1992: 326, García, 2019: 367). Según Gómez-Moreno con destino a la galería de retratos del Generalife, entonces propiedad de los marqueses de Campotejar y tomando como modelo los retratos pintados por Antonio del Rincón, compuso los lienzos de los Reyes Católicos que hoy en día forman parte de los fondos del Museo Casa de los Ti$\operatorname{ros}^{30}$. En cuanto a otras obras que se le atribuyen destacan: El incendio del Hospital Real (1767) y una Trinidad para la iglesia de los Hospitalicos (hoy iglesia del Convento de PP. Agustinos Recoletos) que sigue el modelo del cuadro perdido de Alonso Cano para el convento de franciscanos de San Antonio y San Diego. Por último, en el Museo de Bellas Artes de Granada se conservan otras tantas obras de su mano: Fray Juan de Cetina y Fray Pedro de Dueñas (firmado y fechado en 1778) así como un San Juan Evangelista, una Dolorosa y un San Cristóbal -que por su factura más bien parece obra de su hermano-. Y para completar su biografía habría que añadir que fue uno de los promotores, junto con Diego Sánchez Sarabia y el eclesiástico Antonio Martínez de la Plaza, de la fundación de la Escuela de Dibujo donde estuvo impartiendo clase en la

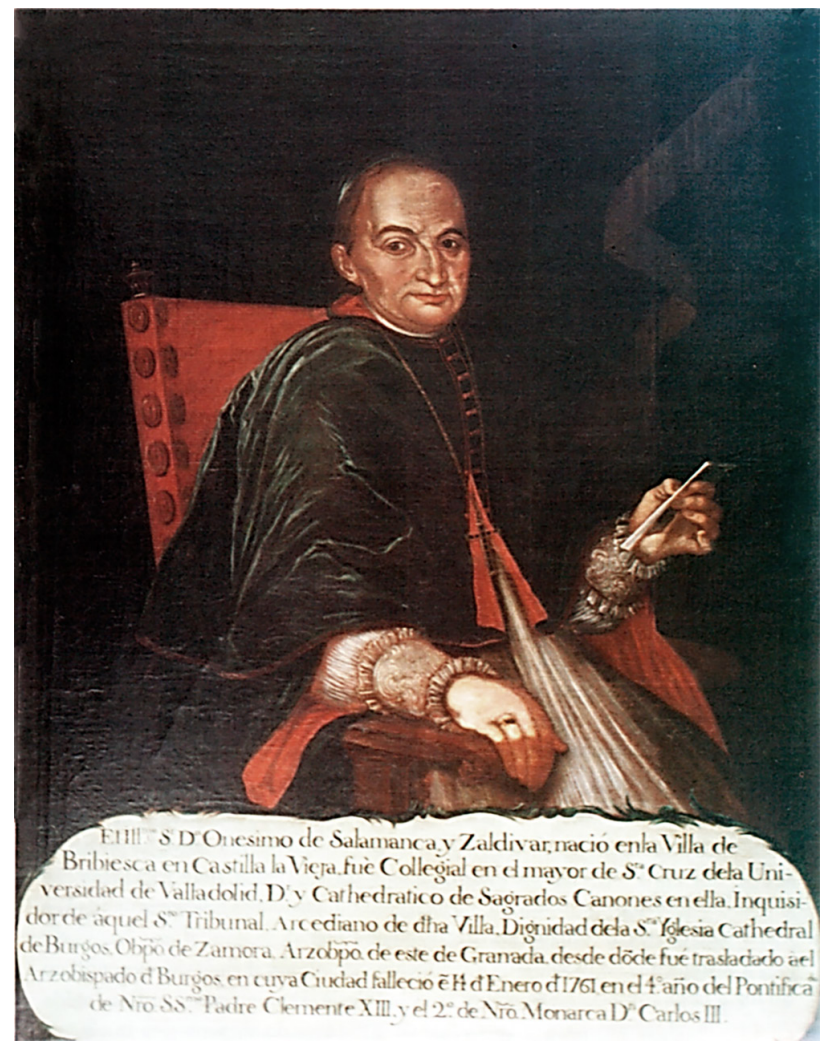

4. Manuel Sanz Jiménez, Onésimo de Salamanca. Curia, Granada

sala de pintura hasta el año de 1784. Falleció en 1803 en la más absoluta pobreza (Moya, 2004: 660).

\section{Los Marín Chaves}

Varios fueron los integrantes de esta destacada familia que se dedicaron a la pintura aunque solo vamos hacer mención de tres de ellos: Juan, Fernando y Lorenzo Marín Chaves. Por lo que se refiere al primero desconocemos, hasta la fecha, cualquier noticia sobre su obra mientras que por lo que respecta a Fernando ocurre todo lo contrario dado que, desde el primer momento, fue un pintor muy apreciado entre sus coetáneos por su gran dominio del dibujo y por su fidelidad a las fuentes gráficas y escritas. En cuanto a la trayectoria del tercero de ellos, Lorenzo, es bastante más desigual que la del anterior puesto que, a pesar de practicar la pintura, se dedicó a otras actividades que fueron las que realmente le proporcionaría los recursos necesarios para sobrevivir. 
Eran hijos del matrimonio, formalizado en 1727, de Sebastián Marín Álvarez y Petronila de Chaves. Esta última estaba vinculada a una familia de plateros, empadronada en la parroquia de las Angustias, muy conocida en la ciudad ${ }^{31}$. En concreto era hija de Pedro de Chaves y María Álvarez de Mendoza mientras que su marido Sebastián era, por su parte, nieto de Melchor Marín y Antonia de Chaves y Enríquez, descendientes, a su vez, de las élites sederas moriscas (Soria, 2009: 25). De hecho, tanto Sebastián como Petronila, al igual que gran parte de la familia de ambos, fueron encausados por "complicidad con el mahometismo" en un proceso inquisitorial celebrado en Granada el 12 de octubre de $1728^{32}$. Esta pareja, además de los hijos anteriormente mencionados, tuvieron otros vástagos. Luis, quien falleció prematuramente a la edad de 15 años; Manuel, que ejerció como preceptor de gramática; Joaquín -con inquietudes artísticas- y Melchora. Cuando Sebastián Marín falleció en 1747, el mayor de sus hijos, Juan (ca. 1732-1791), ejerció como cabeza de familia durante un tiempo y con 20 años ya se ganaba la vida como maestro pintor. A pesar de que hasta el momento apenas tenemos datos en torno a su vida sabemos que falleció soltero siendo enterrado en la capilla de la Buena Dicha de la iglesia parroquial de San Pedro.

Con todo, tal y como se ha expuesto, el más célebre de todos ellos fue Fernando quien llegó a dominar tanto la pintura religiosa como el retrato y el paisaje. Nació en 1737 y falleció el 29 de mayo de 1818, teniendo, por tanto, una dilatada producción pictórica que lo convierte en uno de los artistas más importantes de entre siglos (Gómez, 2019: 504512). Su primera formación la realizó junto a Manuel Sanz Jiménez a quien pronto llegó a superar hasta el punto de instituirse no solo como el pintor granadino más solicitado de su época sino, lo que es más importante, en maestro de toda una generación de jóvenes gracias a su labor como docente en la Escuela de Dibujo. En esta institución desempeñó el cargo de director de Pintura, primero como interino en 1781, ocupando la plaza de Vicente Núñez, y desde el 28 de noviembre de 1786 como titular. Merecimientos a los que habría que sumarle tanto su distinción de académico de mérito por la Real Academia de Bellas Artes de San Fernando el 2 de marzo de 1783 como en 1800 de supernumerario.

En cuanto a sus primeros trabajos documentados nos debemos remontar a la fecha de 1778. Se trata de un encargo realizado por la hermandad de la Aurora, con sede en la ermita de Nuestra Señora de la Aurora y San Nicasio de Priego de Córdoba, por el que recibió unos 1.400 reales (Gómez y Fernández, 2007: 154). El ciclo al que hacemos referencia, distribuido por la nave principal de dicho templo, está conformado por seis cuadros dedicados a la vida de la Virgen: Nacimiento de la Virgen, Presentación en el templo, Desposorios, la Historia de Zacarías, Visitación y Adoración de los Pastores. Para esta misma localidad Marín también pintó la Aparición de la Virgen a san Antonio de Padua que se conserva en la ermita de Nuestra Señora de las Angustias de esta misma localidad (Villar 1995: 658).

De 1785 es el cuadro firmado y conservado en el Seminario Mayor de Granada que representa a San Cecilio y los once mártires de la Alpujarra. Como retratista se le atribuye el retrato de Ricardo Wall conservado en el Museo Naval de Madrid (Téllez, 2006: 13-15). Y por encargo del referido ministro también pintó una vista de las inundaciones del Soto de Roma ocurrida el 25 de marzo de 1772. También se incluye en el catálogo de su obra la Vista de Granada desde el camino del Abellano (Museo de Bellas Artes) (Gámiz-Orihuela, 2009: 121-134). Y por añadidura en la granadina colección Ajsaris se conservan dos cuadros atribuidos a su mano: un lienzo de una Virgen de las Angustias y otro de David vencedor de Goliat.

No obstante, a pesar de ser un artista ya consolidado, su carrera dio un importante giro cuando la Cámara de Castilla le encomendó la realización de algunos de los cuadros que debían adornar los nuevos templos promovidos por la misma en varias localidades del Reino de Granada. En este sentido sobresale una Dolorosa al pie de la cruz (1780) que pintó para el altar mayor de la iglesia parroquial de Alomartes. Aunque, entre estos encargos promovidos por el expresado organismo, su producción más completa es el ciclo de la Vida de la Virgen para la Colegiata de Santa Fe. Dicha serie, realizada a partir de 1786, incluye los siguientes lienzos: La Encarnación, San Joaquín y Santa Ana San Juan Bautista, San Juan Evangelista, El Salvador, San Pedro dirigiendo la palabra a las turbas, San Pedro y San Juan curando al paralítico, El castigo de San Pablo a Elimas, Inmaculada, Santiago, San Hermenegildo, San Fernando en una bataIla, Martirio de San Sebastián y San Carlos asistiendo a los apestados (Gómez, 2019: 505-506).

Por lo que se refiere a Lorenzo, nacido en 1744 y desposado en 1773 con María Marín, su prima lejana, aunque 
sus inicios profesionales fueron como carpintero, finalmente se decantaría por otras especialidades que incluían las de dibujante, pintor y topógrafo. Sin embargo fue un pintor bastante desigual, a diferencia de su hermano Fernando, circunstancia que no mermaría su capacidad de convertirse en uno de los retratistas, junto con Jerónimo de la Chica, más solicitados del último cuarto de siglo. Suyo es el retrato del político y benefactor de la Universidad granadina José Pérez Valiente (colección Universidad de Granada, 1777); o el retrato de la reina Juana de Castilla conservado en esta misma institución (Rodríguez, 2006: 148) [5]. Como dibujante-topógrafo de su mano se conserva en el Archivo de la Real Chancillería de Granada una vista topográfica de 1782 de los términos del Marchal, Cortes y Graena (Ceballos, 2017: 36-37). De igual modo, se atrevió a recomponer cuadros antiguos de los que a veces, llegó a sobrepasar los límites de la restauración. Con todo, el episodio por el que es más conocido tiene que ver con la causa seguida contra el presbítero Juan de Flores por las falsificaciones de la Alcazaba. Marín había sido requerido en 1761 por el citado anticuario para dibujar las piezas, supuestamente originales, que iban apareciendo sucesivamente durante las excavaciones albaicineras dirigidas por el religioso. Se trataba de una serie de detallados dibujos, a tinta china sobre papel de agua, que el grabador Manuel Rivera se cuidó después de pasar a plancha. El objetivo era remitir estas estampas a diferentes eruditos, y posibles, promotores con la idea de obtener el apoyo y dinero necesario para esta particular empresa (Gómez, 2012: 124). Empero, Lorenzo Marín no sería procesado por este trabajo sino por descubrírsele, en un registro efectuado en su vivienda, una pequeña arca con numerosos papeles y dibujos de varios sellos y anillos, imitando letras antiguas, relativos a la falsificación del Voto de Santiago y que habían sido realizados a instancias del propio Flores. Fue mandado a prisión la noche del 12 de junio de 1774 y tras estar retenido durante varios días finalmente sería exculpado retomando su trabajo con total normalidad (Gómez, 2012: 125).

\section{La Chica}

Dos son los miembros de esta familia que tuvieron aptitudes para el manejo de los pinceles. Por una parte, Jerónimo Miguel de la Chica Benavides; y por otra, su propia hija María

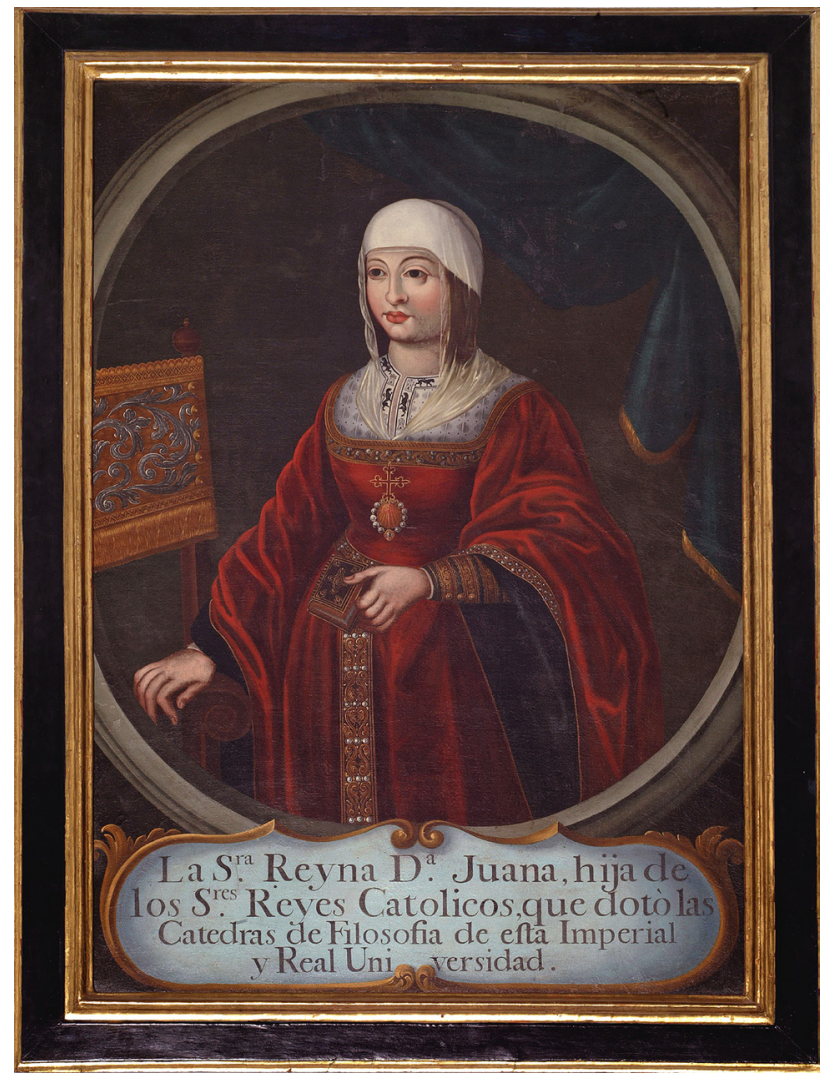

5. Lorenzo Marín Chaves, Juana de Castilla. Universidad, Granada

Seberina. Por lo que se refiere al primero fue uno de esos pintores que, si bien no alcanzó meritoria fama por la fuerza de sus composiciones, sí tuvo una cierta relevancia al practicar un género de gran aceptación como el retrato. Era hijo de Juan José de la Chica Rodríguez, oficial de libros en la tesorería de la fábrica de la Iglesia y de familia originaria de Martos, y de María Josefa de Benavides Jadraque quienes, una vez desposados en 1715, fueron padres, además de nuestro pintor, de Antonio, Cristóbal -de profesión organista- Ana, Tomás y Gertrudis. En relación al primero de los mencionados, Antonio, fue un personaje clave en el contexto cultural granadino dado que, además de ser religioso y sacerdote profeso del convento de Agustinos Calzados de Granada, fue el fundador en 1764 de uno de los primeros periódicos que se editaron en la ciudad, la Gazetilla curiosa, o semanero granadino y útil para el bien común (Aguilar, 1983: 732).

En cuanto al alumbramiento de Jerónimo de la Chica tuvo lugar en octubre de 1728, recibiendo las aguas bautis- 


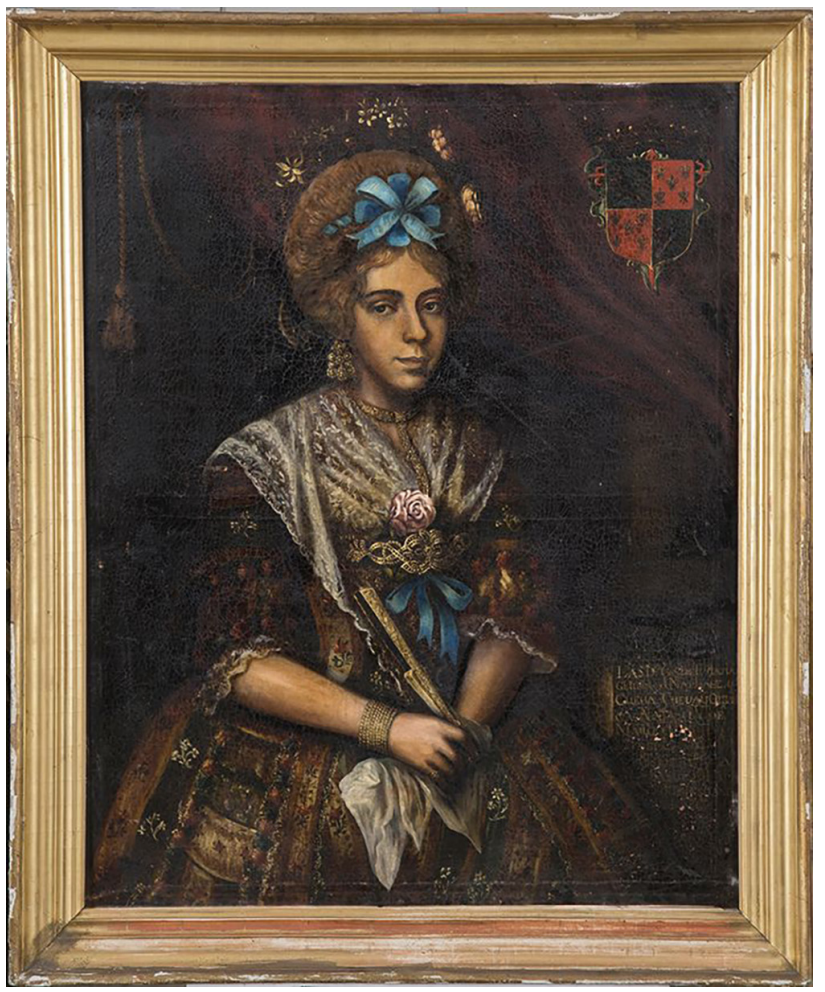

6. Jerónimo de la Chica, Isabel de Chirino de la Cueva, marquesa de Lugros. Colección particular

males el 23 de dicho mes en la parroquia de San Nicolás. A la edad de 22 años ya trabajaba como oficial de pintor y unos diez años más tarde gozaba de la consideración de maestro con taller propio en calle Pastelería, demarcación parroquial de Santa Ana. A pesar de carecer de la gracia, tanto en la composición como en el dibujo, de los grandes maestros granadinos del Barroco se hizo con una exclusiva clientela como retratista. En este sentido, entre sus obras más meritorias, está la serie de retratos, pintados entre 1785 y 1786 , con destino a la galería de personajes relevantes del Colegio-Universidad de Osuna. Adornaban, junto con el resto de retratados por otros tantos pintores, los muros de lo que era la antigua biblioteca y hoy paraninfo universitario (Moreno, 2015). En concreto son de su mano: el Retrato de José María González Robles, Retrato de Pedro Salazar de Mendoza, Retrato de Martín de Aristi, Retrato de Francisco Botello y Córdoba, Retrato de Diego Becerra y el Retrato de Pedro Hurtad o de Gaviria, Retrato de Diego de Avellaneda, Retrato de Juan de Machuca Vargas, Retrato de Fernando de Ojeda,
Retrato de Francisco de Alfaro ${ }^{33}$. Asimismo en los fondos patrimoniales de la Universidad de Granada se conservan dos lienzos suyos: el Retrato de Carlos I. Rey de España (1769) (AA.W.b, 2007: 328) y el de Fray Diego José de Cádiz (Gómez-Moreno, 1994: 389). Y en la misma línea compositiva el Museo Casa de los Tiros custodia el retrato del Padre Juan de Echevarría (1806). En cuanto a los encargos realizados para la élite dentro de su faceta como retratista destaca el lienzo de Isabel de Chirino de la Cueva, segunda esposa de Luis José de Mora a la sazón V marqués de Lugros (col., part.) [6]. En relación a su producción religiosa en 1786 hizo entrega de un óleo de Nuestra Señora de las Angustias para el retablo mayor de la iglesia de Lecrín (Sánchez, 1997: 106).

De su unión con Nicolasa Garzón tuvo a Nicolás, religioso y estudiante universitario, Francisca, Jerónima, Gertrudis y María Serafina de La Chica y Garzón. Esta última desde muy joven manifestó grandes inquietudes artísticas. Además de auxiliar a su padre en su taller, su mayor logro fue convertirse en la única mujer que figura como inscrita en la Escuela de Dibujo, en concreto el 22 de enero de 1788, tras presentar un dibujo de San Cayetano. Pero a pesar de que no pudo asistir de manera presencial a dicho centro, dada su condición de fémina, sí estuvo inmersa en la habitual dinámica académica al quedar su instrucción a cargo del escultor, y profesor, Jaime Folch (Gómez, 2004: 86). Sus amplias dotes con el dibujo quedaron, de igual modo, patentes cuando presentó en 1797, fuera del concurso de los Premios Generales organizados por la Real Sociedad Económica de Amigos del País de Granada de ese año, un dibujo dentro del apartado de figuras. Dicha obra mereció el aprecio del marqués de Villaalegre hasta el punto de recompensarla económicamente por ello.

En definitiva, y a modo de conclusión, podemos aseverar que a lo largo del siglo XVIII casi todos los jóvenes que iniciaron su formación como pintores en la ciudad de Granada lo hicieron, prácticamente, bajo la misma praxis de aprendizaje que en la anterior centuria. Tal es así que las pautas de trasmisión de las técnicas y recursos estilísticos siguieron las fórmulas propias de los artistas del Barroco. El taller familiar, por tanto, se convirtió en el ámbito habitual de conocimiento. Un saber que estaba fundamentado en un uso reiterativo de pautas que, a su vez, fueron las que llevaron a sus integrantes a una ingente producción de obras tardobarrocas basadas en modelos repetitivos, en cuanto a composiciones 
y temas iconográficos se refiere, y con una menor base estética que en etapas anteriores. Para determinados artistas estas circunstancias, a la postre, les sumirían en un estancamiento a nivel creativo y del cual muy pocos consiguieron salir. Con todo, gracias a la instauración de la Escuela de Dibujo, y sobre todo a la figura de Fernando Marín como docente de la misma, se generó el suficiente interés por parte de esta institución por refrescar, atendiendo a las nuevas normas academicistas, la forma adocenada que mostraban gran parte de los estudiantes que pasaban por sus aulas y cuya primera instrucción la habían realizado al amparo de estos talleres gremiales.

\section{Notas}

1 Jerónimo, su padre, era hijo de Juan de Rueda Navarrete y Gabriela Carrillo de Rueda, y no del pintor Esteban de Rueda como algunos investigadores afirman. Había nacido en 1671 y fue bautizado en la parroquia de San Andrés el 5 de noviembre de ese año y falleció en 1750. En su caso la familia paterna no tenía nada que ver con el mundo del arte. El padre del pintor era escribano del rey, su tío Juan ejerció como abogado y fiscal del arzobispado, y otro tío de nombre Mateo era mercader. Por lo demás, a la edad de 10 años la familia se instaló en la parroquial de San José donde Jerónimo se formó, entre 1685 y 1690 , en el entorno de Juan de Sevilla quien a su vez en este último año se convertiría en su cuñado al casarse con su hermana Teresa.

2 Archivo Diocesano, Granada (AD, Granada). Expediente matrimonial entre Jerónimo de Rueda y Cipriana Josefa Pérez, 5 de septiembre de 1697. Mic. $1459679-258$.

3 Archivo Parroquial de San José, Granada (APSJ, Granada). Libro de defunciones de San Miguel 1729-1754, fol. 114 v.

4 APSJ, Granada. Padrones de la parroquia de San Miguel.

5 APSJ Granada. Libro de desposorios San Nicolás 1665-1713, fol. 70.

6 APSJ, Granada. Libro de Bautismos de San Miguel. 1674-1724, fol. 240

7 Fueron padres de Rita, María, Josefa, José y Vicente.

8 Archivo Diocesano, Granada (AD, Granada) Expediente matrimonial de Basilio Damián Marchena con Cecilia Francisca de Alcober, 17 de noviembre de 1735. Mic. 1325834-93.

9 Archivo Histórico Provincial, Granada (AHP, Granada). Catastro. Oficios. Libro 1271. Fol. 59.

10 APSJ, Granada. Libro de bautismos San Miguel, 3, fol. 302.

11 Felipe en 1786 desposó con María Micaela Ramos en 1786.

12 AHP, Granada. Libro de Juntas, fol. 331.

13 Archivo Catedral, Granada. (ACG, Granada). Leg. 169. Recibos. Cobró el 24 de febrero, 844,16 reales.

14 Viuda de Francisco Muros. Contrajo esponsales en la parroquia de San José. (APSJ, Granada) Desposorios de San José 1674-1730, fol. 140 v.

15 Posiblemente sea el padre del grabador Francisco de la Torre (1766-1800) activo este último en Antequera y Málaga.

16 Los lienzos de Jacinto Mendoza aparecen inventariados con los números 0262/04 al CE 0270/ 04. AA. W., 2007a: 148-150.

17 APSJ, Granada. Libro de bautismos San Miguel, fol. 208.

18 Contrajo esponsales en 1727 con Jerónima Idáñez, la familia se completaba con José Mario y Antonia.

19 AHP, Granada. Catastro. Respuestas particulares del vecindario secular de personal cualificado por oficios. Libro 1270, fol. 248.

20 AD, Granada. Mic. 1297433, fol. 28 V . Fue bautizado el 29 de abril su padrino José de Entrala y Rueda, secretario de Cámara de Hijosdalgo.

21 Archivo Histórico Nobleza, Toledo (AHN, Toledo). Luque C. 374. D. 418-435. Correspondencia remitida a Francisco de Paula Fernández de Córdoba por Vicente Núñez 1773, fol.12.

22 Miguel nació en 1715 y falleció en 1779. Rosalía nació en 1723.

23 Archivo Parroquial de San Pedro, Granada (APSP, Granada). Libro de Defunciones de la parroquia de San Juan 1703-1765, fol. 232.

24 AD, Granada. 20 Expediente matrimonial de Nicolas Sanz con Severiana Mariana, 1712. Mic. 1518888.

25 Casó con Nicolasa Ajedo y establecieron su domicilio en la parroquia de San Nicolás.

26 APSJ, Granada. Libro 3 de Bautismo de San Miguel, fol. 231.

27 Archivo Parroquial de Santa Ana, Granada (APSA, Granada). Libro 10 de entierros 1756-1790, fol. 140.

28 Archivo del Instituto Gómez-Moreno de la Fundación Rodríguez-Acosta, Granada (AIGM, Granada). Leg. CXXXI, Escultores, fol. 46.

29 Archivo Capilla Real de Granada (ACR, Granada). Leg. 96. «Gastos de Orfebrería 1770-1789». 27 de marzo de 1788.

30 AIGM, Granada. Leg. CXVI, fols. 188-189.

31 Era hijo del matrimonio conformado por Melchor Marín Alférez, médico y viudo de Gabriela León, quien desposó en 1668 con Antonia de Chaves -hija de Isidro de Chaves e Isabel Enríquez-. De esta unión nació Luis Marín que desposó con Leonor Álvarez quienes fueron padres de Sebastián Marín Álvarez esposo de Petronila de Chaves.

32 AHP, Granada. Expediente de presos. 3206-20.

33 Decreto 346/2004, de 18 de mayo por el que se declara Bien de Interés Cultural, con la categoría de Monumento, el Colegio-Universidad de la Purísima Concepción en Osuna (Sevilla). 


\section{Bibliografía}

AGUILAR PIÑAL, Francisco (1983), Bibliografía de autores españoles del siglo XVIII, vol. II, CSIC, Madrid.

ALABAU MONTOYA, José (2015), «Aproximación a la biografía de Fr. Rodrigo de Sigüenza. El alma "organizadora” de la orden de San Juan

de Dios", Archivo Hospitalario, n. ${ }^{\circ} 13$, pp. 371-418.

AA. W. (2007a), Inventario de pintura, dibujo y escultura. Museo de Bellas Artes de Granada, Junta Andalucía, Granada.

AA. W. (2007b), Inventario del patrimonio artístico de la Universidad de Granada, Universidad, Granada.

CASTAÑEDA BECERRA, Ana María (2006), El retrato granadino en el Barroco, Universidad, Granada.

CEBALLOS GUERRERO, Antonio (2017), «Dibujando el conflicto. La cartografía del Altiplano granadino en los pleitos del Archivo de la Real

Chancillería de Granada», Boletín del Centro de Estudios Pedro Suárez, n. ${ }^{\circ}$ 30, pp. 31-60.

GALLEGO BURÍN, Antonio (1996), Granada. Guía artística e histórica de la ciudad, Comares, Granada.

GÁMIZ, Antonio y ORIHUELA, Antonio (2008), «Una vista del paisaje de Granada encargada por el conde de Maule al pintor Fernando Marín hacia 1798", Goya, n. ${ }^{\circ} 323$, pp. 121-134.

GARCÍA LUQUE, Manuel (2019), «Las copias y el copiado de pintura italiana en Granada durante los siglos del Barroco», en GARCíA CUE-

TO, David (dir.), La pintura italiana en Granada. Artistas y coleccionistas, originales y copias, Universidad, Granada, pp. 433-469.

GIMÉNEZ SERRANO, José (1846), Manual del artista y del viagero, J. A. Linares, Granada.

GÓMEZ-MORENO GONZÁLEZ, Manuel (1992), Guía de Granada, Universidad, Granada.

GÓMEZ ROMÁN, Ana María (2004), «Un juego de espejos la figura de la mujer y la Real Academia de Bellas Artes», Cuadernos de Arte de la Universidad de Granada, n. ${ }^{\circ}$ 35, pp. 81-91.

GÓMEZ ROMÁN, Ana María (2012), «Artistas y anticuarios en las falsificaciones del Albaicín», en SÁNCHEZ LÓPEZ, Elena, MARíN DÍAZ, Purificación y GÓMEZ ROMÁN, Ana María, En torno a la Granada falsificada, Diputación, Granada, pp. 76-126.

GÓMEZ ROMÁN, Ana María (2019), «Empleo y uso de la copia italiana por los pintores granadinos del siglo XVIII y la Escuela de Dibujo», en GARCÍA CUETO, David (dir.), La pintura italiana en Granada. Artistas y coleccionistas, originales y copias, Universidad, Granada, pp. 495-512.

HERNANDO, Lesmes (1857), Catálogo de los retratos de los personajes célebres, Antonio García, Madrid.

LÓPEZ-GUADALUPE MUÑOZ, Juan Jesús y LÓPEZ-GUADALUPE MUÑOZ, Miguel (1996), «Artes y oficios artísticos en Granada a mediados del XVIII», Espacio, Tiempo y Forma, n. ${ }^{\circ}$ 9, pp. 157-188.

MARTín OJEDA, Marina y VALSECA CASTILLO, Ana (2000), Écija y el Marquesado de Peñaflor, de Cortes de Graena y de Quintana de las Torres, Fundación de los Excmos. Sres. Marqueses de Peñaflor y de Cortes de Graena, Écija.

MOYA MORALES, Javier (2004), Manuel Gómez-Moreno González. Obra dispersa e inédita, Fundación Rodríguez-Acosta, Granada.

MORENO DÍAZ, Juan Manuel (2015), La colección de retratos varones ilustres de la antigua Universidad de Osuna con un epítome de sus vidas, Fundación Pública de Estudios Universitarios, Osuna.

REYES RUIZ, Concepción (1995), La iglesia de la Asunción de Cúllar (estudio artístico y constructivo), Ayuntamiento, Granada.

RODRÍGUEZ DOMINGO, José Manuel (2006), «El patrimonio artístico del Colegio de San Pablo: de la Compañía de Jesús a la Universidad de Granada», en AA. W., Obras Maestras del Patrimonio de la Universidad de Granada. Catálogo. Volumen I. Estudios, Universidad, Granada, pp. 127-164.

RODRÍGUEZ RUIZ, Delfín (1990), «Diego Sánchez Sarabia y las antigüedades árabes de España: los orígenes del proyecto», Espacio, Tiempo y Forma, n. ${ }^{\circ}$, pp. 225-257.

SALAS, Xavier (1966), Noticias de Granada reunidas por Ceán Bermúdez, Granada, Universidad.

SORIA MESA, Enrique (2009), «Una gran familia. Las élites moriscas la Reino de Granada», Estudis, n. ${ }^{\circ}$ 35, pp. 9-35.

SORIA MESA, Enrique (2012), «Los moriscos que se quedaron. La permanencia de la población de origen islámico en la España Moderna (Reino de Granada)", Vínculos de Historia, n. ${ }^{\circ}$, pp. 205-230.

TÉLLEZ ALARCIA, Diego (2006), El ministerio Wall. La «España discreta» del «ministro olvidado», Fundación de Municipios «Pablo Olavide Sevilla", Sevilla. 